\title{
Nanopore sequencing reveals full-length Tropomyosin 1 isoforms and their regulation by RNA binding proteins during rat heart development
}

Jun $\mathrm{Cao}^{1+}$, Andrew L. Routh ${ }^{1,2}$ and Muge N. Kuyumcu-Martinez ${ }^{1,3,4^{*}}$

${ }^{1}$ Department of Biochemistry and Molecular Biology, University of Texas Medical Branch, Galveston, Texas

${ }^{2}$ Sealy Centre for Structural Biology and Molecular Biophysics, University of Texas Medical Branch, Galveston, Texas

${ }^{3}$ Institute for Translational Sciences, University of Texas Medical Branch, Galveston, Texas

${ }^{4}$ Department of Neuroscience, Cell Biology, and Anatomy, University of Texas Medical Branch, Galveston, Texas

+Present address: Cardiology Department, Boston Children's Hospital, Harvard Medical School, Boston, MA 02115

${ }^{*}$ Corresponding author: Muge N. Kuyumcu-Martinez

E-mail: nmmartin@utmb.edu

Running title: Developmental regulation of Tropomyosin 1 isoforms

Keywords: alternative splicing, long read DNA sequencing, Tropomyosin, RNAbinding proteins, heart development 


\section{ABBREVIATIONS}

AS: alternative splicing

E20: embryonic day 20

6mo: 6-months old

KD: knock down

TPM1: Tropomyosin 1 


\begin{abstract}
Alternative splicing (AS) contributes to the diversity of the proteome by producing multiple isoforms from a single gene. Although short-read RNA sequencing methods have been the gold standard for determining AS patterns of genes, they have a difficulty in defining full length mRNA isoforms assembled using different exon combinations. Tropomyosin 1 (TPM1) is an actin binding protein required for cytoskeletal functions in non-muscle cells and for contraction in muscle cells. Tpm1 undergoes AS regulation to generate muscle versus non-muscle TPM1 protein isoforms with distinct physiological functions. It is unclear which full length Tpm1 isoforms are produced via AS and how they are regulated during heart development. To address these, we utilized nanopore longread cDNA sequencing without gene-specific PCR amplification. In rat hearts, we identified full length Tpm1 isoforms composed of distinct exons with specific exon linkages. We showed that Tpm1 undergoes AS transitions during embryonic heart development such that muscle-specific exons are connected together generating predominantly muscle specific Tpm1 isoforms in adult hearts. We found that the RNA binding protein RBFOX2 controls AS of rat Tpm1 exon 6a, which is important for cooperative actin binding. Furthermore, RBFOX2 regulates Tpm1 AS of exon 6a antagonistically to the RNA binding protein PTBP1. In sum, we defined full length Tpm1 isoforms with different exon combinations that are tightly regulated during cardiac development and provided insights into regulation of Tpm1 AS by RNA binding proteins. Our results demonstrate that nanopore sequencing is an excellent tool to determine fulllength AS variants of muscle enriched genes.
\end{abstract}




\section{INTRODUCTION}

Gene regulation by alternative splicing (AS) is an important contributor to development and tissue identity (Baralle and Giudice 2017). AS not only controls gene expression but also generates different isoforms of genes. Genome-wide analyses indicate that the majority of human genes undergo AS (Wang et al. 2008). Currently, many computational approaches based on short read RNA-sequencing are available to investigate AS patterns. However, with these techniques it can be difficult to determine the connectivity of multiple exons in a given transcript. This becomes more challenging if a given gene has many potential isoforms. Recent advances in nanopore sequencing technology allow sequencing of ultra-long DNA sequences (Lu et al. 2016) (Jain et al. 2018). The Oxford MinION sequencer is a portable device that provides realtime, high-throughput and long-read sequencing with $<10 \%$ error rate (de Jong et al. 2017; Oikonomopoulos et al. 2016; Wang et al. 2020). This technology, therefore, is very attractive to study complex AS patterns in the context of full-length transcripts.

TPM1 is a coiled-coil protein that wraps around the actin molecules and provides stability to actin filaments. TPM1 is the predominant tropomyosin gene expressed in cardiac muscle and plays a significant role in muscle contraction (Bai et al. 2013). TPM1 is required for myofibril organization (Thomas et al. 2010), myocardial contraction (Wolska and Wieczorek 2003), and cardiac development (England et al. 2017). Mutations or aberrant expression of TPM1 are associated with familial hypertrophic cardiomyopathy (Jongbloed et al. 2003; Marques and de Oliveira 2016; Muthuchamy et al. 1999;

Thierfelder et al. 1994), dilated cardiomyopathy (Karam et al. 2011; Redwood and Robinson 2013) and heart failure (Rajan et al. 2010). TPM1 has 15 exons, several of 
which are alternatively spliced, generating many gene isoforms generated via AS that are tissue specific and developmentally regulated (Gooding et al. 2013a). These multiple isoforms render distinct functions including cytoskeleton support and muscle contraction in the heart (Gunning et al. 2015; Lin et al. 2008; Perry 2001; Schevzov et al. 2011). However, it is still unclear what mechanisms dictate highly coordinated AS of Tpm1 that impacts its expression and function in a cell- and development-specific manner. In this study, we used nanopore sequencing to identify full length transcripts of Tpm1 gene with complex AS patterns in rat hearts at different developmental stages.

RBFOX2 is an RNA binding protein, which regulates AS by binding to a highly conserved motif ((U)GCAUG) in pre-mRNAs (Huang et al. 2012; Lovci et al. 2013; Sun et al. 2012; Yeo et al. 2009). RBFOX2 is important for muscle differentiation (Sebastian et al. 2013), maintaining muscle mass (Singh et al. 2018a), and sustaining muscle function (Gallagher et al. 2011). We and other groups have shown that RBFOX2 is involved in cardiovascular diseases including hypoplastic left heart syndrome (Homsy et al. 2015; McKean et al. 2016; Verma et al. 2016), heart failure (Wei et al. 2015), and diabetic cardiomyopathy (Nutter et al. 2017; Nutter et al. 2016). RBFOX2 binding sites are enriched near alternative exons that are developmentally regulated postnatally in the heart (Misra et al. 2020), suggesting a role for RBFOX2 in regulation of AS during heart development.

Using nanopore cDNA sequencing, we identified full length Tpm1 isoforms with unique exon combinations that are regulated during rat heart development. We found that muscle and non-striated muscle Tpm1 isoforms was generated via AS of specific exons during rat heart development. We uncovered that RBFOX2 regulates AS of rat Tpm1 exon 
6a. Furthermore, we found that RBFOX2 and PTBP1 antagonistically control AS of Tpm1 exon6a. Overall, our results reveal that $T p m 1$ spliced isoforms are tightly regulated during rat cardiac development and that RNA binding proteins RBFOX2 and PTBP1 have opposing roles in controlling developmentally regulated Tpm1 AS. Our findings have broad implications in defining complex alternative splicing patterns of abundant cardiac muscle-enriched genes using nanopore cDNA sequencing. 


\section{RESULTS}

\section{Nanopore sequencing identifies full length $T p m 1$ isoforms that undergo alternative splicing transitions during rat heart development}

Tpm1 has many different isoforms generated via AS (Gooding et al. 2013a). To determine the exact combination of exons in full length Tpm1 isoforms in the heart at different developmental stages, we used total RNA from embryonic day 20 (E20, n=3) and 6-month $(6 \mathrm{M}, \mathrm{n}=3)$ rat hearts and generated cDNA for nanopore sequencing on the Oxford Nanopore Technologies's MinION. We picked late embryonic and adult stages because between these stages the heart undergoes structural and functional changes important for cardiac output and contractility relevant to TPM1 function.

We obtained $\sim 310$ '000-740'000 reads spanning 3000-4300 unique mRNAs, 190413 of which had a coverage of greater than 100 reads that were mapped to the rn6 genome using Minimap2 (Li 2018). We obtained average of 200,000 reads mapped to Tpm1. Reads that were mapped to Tpm1 are illustrated in Figure 1A. In E20 rat hearts, we identified Tpm1 isoforms generated via AS of exons 1a/1b, 2a/2b, 6a/6b, 9a, 9b and 9d (Figure 1A, top panel), consistent with previous findings that these mutually exclusive exons are alternatively spliced (Gunning et al. 2005b; Moraczewska et al. 1999). Strikingly, at this developmental stage Tpm1 transcripts displayed two distinct $3^{`}$ ends defined by exon usage of either exon $9 b$ or $9 d$ that contain both $3^{\prime}$ UTR and coding region (Figure 1A, top panel). There were also transcripts that ended with exon 9a (Figure 1A, 1B and $1 \mathrm{C})$. The differences in the $3^{\circ}$ end of Tpm1 was generated via AS of terminal exons 9a-9b and 9d (Figure 1A). Inclusion of exon 9b resulted in short Tpm1 isoforms whereas inclusion of exon 9d generated long Tpm1 isoforms (Figure 1A, top panel). It has been 
previously shown that Tpm1 isoforms that contain exon 9a-9b are primarily expressed in striated muscle (muscle-specific isoform), and that contain exon 9d are expressed in smooth muscle and other cell types (non-striated muscle isoform, in short non-muscle) (Gunning et al. 2005b; Moraczewska et al. 1999). Cardiac output increases and contractions become more coordinated at adult stages in comparison to embryonic stages. Consistent with this, muscle specific Tpm1 isoforms that end with exon 9b were predominantly expressed at adult stages. On the other hand, non-muscle Tpm1 isoforms that end with exon 9d (Figure 1A, bottom panel) were present in embryonic hearts but were dramatically decreased in adult hearts.

We mapped all the exons and obtained full length Tpm1 transcripts using the nanopore reads (Supplemental Excel File 1). In rat hearts, Tpm1 exons 1a, 2b, 6b, 9a and $9 \mathrm{~b}$ were more frequently used (Figure 1A, 1B and 1C). Several Tpm1 transcripts started with exon $2 \mathrm{~b}$ instead of exon $1 \mathrm{a}$ or exon $1 \mathrm{~b}$ (Figure $1 \mathrm{~B}$ and $1 \mathrm{C}$ ). Interestingly, several Tpm1 transcripts ended with exon 7 or 8 instead of exon 9a, 9d or 9d (Figure 1B and $1 \mathrm{C})$. We also found unique linkages between internal and terminal exons in a given Tpm1 transcript. For example, exon 9b was present in all muscle specific Tpm1 transcripts that included exon 9a in rat hearts (Figure 1A, 1B and 1C). This is in agreement with predominant expression of Tpm1 isoforms that contain both exon 9a and 9b at adult stages when the heart contracts more coordinately in comparison to the embryonic heart. Similar to exon9a-9b linkage, we found that exon 2a was almost always included in nonmuscle Tpm1 isoforms that ended with exon 9d (Figure 1A, top panel and 1B). Exon 2a9d containing isoforms were barely detectable in adult rat hearts (Figure 1A, bottom panel and 1C). Also, Tpm1 isoforms that contain exon 6a were present scarcely at E20 rat 
hearts (Figure $1 \mathrm{~A}$ and $1 \mathrm{~B}$ ), but they were diminished in adult rat hearts (Figure $1 \mathrm{~A}$ and 1C). When we examined the most abundant Tpm1 full length transcripts in E20 hearts, we noticed that alternative exons $1 b, 2 a, 6 a$ and $9 d$ were more frequently used in Tpm1 full transcripts (Figure 1B) than that adult rat hearts (Figure 1C). These exons are associated with non-striated muscle isoforms of Tpm1.

To validate the nanopore sequencing data and assess expression of different Tpm1 isoforms in embryonic rat hearts at E13, E16, E18, E20, at 1-day old (D1) vs 6months old stages, we designed primers to determine the inclusion of exons $6 a, 6 b, 9 b$ and 9d via RT-qPCR (Table S1). Consistent with the nanopore sequencing data, the expression of $T p m 1$ transcripts that include muscle enriched exons $6 \mathrm{~b}$ and $9 \mathrm{~b}$ gradually increased dramatically after birth (Figure 1D) and expression of non-muscle exons 6a and 9d containing Tpm1 transcripts were downregulated after birth (Figure 1D). Exons 9a and $9 \mathrm{~b}$ are important determinants for actin binding affinity of TPM1 and interactions with troponin complex in the presence or absence of $\mathrm{Ca}^{2+}$ (Hammell and HitchcockDeGregori 1996; Moraczewska et al. 1999). The exon 6a is required for actin binding and replacing exon $6 b$ with exon $6 a$ increases TPM1 actin binding affinity (Hammell and HitchcockDeGregori 1997). The differences in inclusion of internal exon 6a, exon 2a and terminal exons $9 a-9 b$ and $9 d$ in Tpm1 isoforms expressed in rat hearts correlates with the actin binding activity of Tpm1 during muscle contraction at different developmental stages.

The RNA binding protein RBFOX2 controls AS of developmentally regulated exons of Tpm1 
RBFOX2 is an AS regulator abundantly expressed in skeletal and heart muscle (Nutter et al. 2017; Nutter et al. 2016; Singh et al. 2018b; Singh et al. 2014). RBFOX2 binding sites are enriched in introns flanking alternative exons that are regulated during postnatal mouse hearts (Kalsotra et al. 2008). To determine the role of RBFOX2 in developmentally regulated AS of Tpm1, we depleted RBFOX2 in embryonic rat heart derived H9c2 cells (Figure 2A). We performed RT-qPCR to validate AS of mutually exclusive exons $6 \mathrm{~b}$ vs $6 \mathrm{a}$. Tpm1 isoforms including exon 6a were dramatically increased upon RBFOX2 depletion (Figure 2B). These results show that RBFOX2 KD altered AS and of Tpm1 exon 6a, which is present in non-muscle Tpm1 isoforms (Figure 1A) (Gunning et al. 2005b; Moraczewska et al. 1999).

The RNA binding protein PTBP1 has been shown to regulate Tpm1 AS (Gooding et al. 2013a; Lin and Tarn 2005; Llorian et al. 2010; Mullen et al. 1991; Xue et al. 2009). RBFOX2 has been shown to regulate AS and mRNA levels of PTBP family member (Jangi et al. 2014). To rule out the possibility that the effect of RBFOX2 on AS of Tpm1 was mediated via changes in PTBP1, we examined PTBP1 protein levels in control and RBFOX2 depleted H9c2 cells. RBFOX2 KD did not affect PTBP1 protein levels (Figure 2A).

\section{Ectopic expression of RBFOX2 partially rescues developmentally regulated AS of}

\section{Tpm1 in RBFOX2 depleted cells}

We next tested if ectopic expression of RBFOX2 can rescue Tpm1 AS changes in RBFOX2 depleted cells. We expressed GFP tagged RBFOX2 in RBFOX2-depleted H9c2 cells and found that GFP-RBFOX2 protein was expressed at low levels similar to the 
endogenous RBFOX2 levels in RBFOX2 KD cells (Figure 2C, lane 1 vs 3 ). We tested AS of Tpm1 exons 6a/6b in RBFOX2 KD cells expressing either GFP or GFP-RBFOX2. Expression of GFP-RBFOX2 partially rescued AS changes of Tpm1 exon 6a/6b (Figure 2D), suggesting that RBFOX2 is a regulator of AS of developmentally regulated Tpm1 alternative exon $6 a$.

\section{RBFOX2 and PTBP1 antagonistically control developmentally regulated AS of}

\section{Tpm1}

The RNA binding protein PTBP1 is a known regulator of Tpm1 AS of mutually exclusive exons 2a/2b (Gooding et al. 2013a; Mullen et al. 1991) and exons 6a/6b (Xue et al. 2009) and terminal exons (Lin and Tarn 2005; Llorian et al. 2010). AS of these Tpm1 exons are also developmentally regulated. We found that RBFOX2 also regulates AS of exons $6 \mathrm{a} / 6 \mathrm{~b}$. To determine where these RNA binding proteins bind with respect to the developmentally regulated alternative exons of $T p m 1$, we examined the enhanced crosslinking immunoprecipitation RNA-seq (eCLIP) data for RBFOX2 and PTBP1 from ENCODE (Consortium 2012; Davis et al. 2018). We found binding clusters for both PTBP1 and RBFOX2 mapped in or near Tpm1 exons 6a in both eCLIP experiments, suggesting that these RNA binding proteins may regulate Tpm1 AS antagonistically (Figure 3A).

PTBP1 binding sites were present in both eCLIP experiments near Tpm1 exons 6a, 6b, and 9b (Figure 3A). To validate the regulation of these exons by PTBP, we knocked down PTBP proteins using PTBP1/2 siRNAs in embryonic rat heart derived H9c2 cells. PTBP depletion led to downregulation of muscle specific Tpm1 transcripts that end 
with exon 9b (Figure 3B). There was no significant change in non-muscle Tpm1 isoforms that end with exon 9d in PTBP1 KD cells (Figure 3C), consistent with lack of PTBP1 binding sites within or near this exon in Tpm1 pre-mRNA (Figure 3A).

Inclusion of Tpm1 exon 6a was inhibited in PTBP depleted H9c2 cells (Figure 3D). This was contrary to what was observed in RBFOX2 depleted H9c2 cells (Figure 2B and 2D). These findings indicate that RBFOX2 and PTBP1 antagonistically control developmentally regulated AS of Tpm1 exon 6a, contributing to the generation of Tpm1 isoforms with different actin binding capabilities.

To better understand how Tpm1 muscle specific isoforms are regulated by RBFOX2 and PTBP1 during rat heart development, we checked RBFOX2 and PTBP1 protein levels during rat heart development. Both PTBP1 and RBFOX2 protein levels were abundant at embryonic stages and 1-day old pups (Figure 3E) but levels went down in adult stages. Because PTBP1 is a repressor of muscle specific Tpm1 isoforms, low levels of PTBP1 in adult rat hearts (Figure 3E) correlated well with predominant expression of Tpm1 muscle specific isoforms in adult hearts (Figure 1A, bottom panel and $1 \mathrm{C})$.

\section{Developmentally regulated AS patterns of TPM2 and TPM3}

There are four family members of TPM in vertebrates namely TPM1, TPM2, TPM3 and TPM4. TPM1 and TPM2 are predominantly expressed in muscle and are involved in contraction (Dube et al. 2014; Jagatheesan et al. 2010; Wieczorek et al. 2008; Yin et al. 2015), whereas TPM3 and TPM4 are enriched in non-muscle cells supporting actin cytoskeleton (Bailey 1948; Dube et al. 2014; Gunning et al. 2008; Gunning et al. 2005a; 
Helfman et al. 1986; Lin et al. 2008; Marston and Redwood 1993; Perry 2001; Rao et al. 2012; Yin et al. 2015). To determine whether AS of other TPM genes were also regulated during rat heart development, we examined our nanopore sequencing data. Tpm2 and Tpm3 displayed AS transitions between embryonic and adult stages in rat hearts as well as changes in its expression levels (Figure 4A and 4B top vs bottom panels). Tpm2 isoforms that end with exon 9d were predominant in adult rat hearts (Figure 4A). Similar to $T p m 1, T p m 2$ exons $6 \mathrm{a} / 6 \mathrm{~b}$ and $9 \mathrm{~b} / 9 \mathrm{~d}$ differentially spliced during rat heart development (Figure 4A vs Figure 1A, 1B and $1 \mathrm{C}$ ). Tpm3 exons $1 \mathrm{a} / 1 \mathrm{~b}$, exons $6 \mathrm{a} / 6 \mathrm{~b}$ and exons $9 \mathrm{a} / 9 \mathrm{~b}$ were also developmentally regulated. Interestingly, AS of Tpm4, which is enriched in nonmuscle cells, was not regulated via AS during rat heart development (Figure 4C). 


\section{DISCUSSION}

$T p m 1$ is an essential gene required for organization of the myofibril (Thomas et al. 2010), myocardial contraction (Wolska and Wieczorek 2003), and heart development (England et al. 2017). Tpm1 has 15 exons, in which internal exons $1 \mathrm{a} / 1 \mathrm{~b}, 2 \mathrm{a} / 2 \mathrm{~b}$ and $6 \mathrm{a} / 6 \mathrm{~b}$ and terminal exons 9a, 9b, 9c and 9d are alternatively spliced (Crawford and Patton 2006; Dye et al. 1998; Geeves et al. 2015; Gooding et al. 2013b; Lin and Tarn 2005; Lin et al. 2008; Mullen et al. 1991). AS of Tpm1 isoforms are tissue- and development- specific and exhibit distinct physiological functions (Gunning et al. 2015; Lin et al. 2008; Perry 2001; Schevzov et al. 2011) including cytoskeleton support for almost every eukaryotic cells and muscle contraction for striated muscle cells (Dube et al. 2014; Jagatheesan et al. 2010; Wieczorek et al. 2008; Yin et al. 2015). Full length Tpm1 isoforms that are generated via extensive AS regulation in different cell types and at different developmental stages have not been obvious using short read RNA sequencing methods. It is because short read RNA sequencing is unable to provide direct information about how different exons are connected and incorporated into full length transcripts to generate different Tpm1 isoforms. In addition, bias is generated from fragmentation during library preparation. Using nanopore long read sequencing by MinION, we were able to detect full length isoforms of abundant cardiac genes including tropomyosin family members without extensive RNA manipulation and gene specific PCR amplification.

Nanopore sequencing identified full length Tpm isoforms with different internal and terminal exon combinations in rat hearts that are regulated during development. We defined striated muscle vs non-striated muscle Tpm1 isoforms based on the specific exon combinations and internal-terminal exon linkages in embryonic vs adult hearts. We also 
observed that striated muscle specific Tpm1 isoforms were abundantly expressed at both embryonic and adult stages, but they became the predominant isoform in adult hearts. Embryonic rat hearts displayed more non-striated muscle Tpm1 isoforms in comparison to adult rat hearts. Loss of non-muscle specific Tpm1 isoforms in adult rats is in agreement with the increased muscle contraction capability of adult hearts in comparison to embryonic hearts.

We identified RBFOX2 as a regulator of developmentally regulated AS of Tpm1, consistent with a recent study has identified a splicing change in TPM1 in mouse embryos in which RBFOX2 was conditionally ablated in neural crest cells (Cibi et al. 2019). Our work provide evidence that changes in Tpm1 AS may contribute to heart and muscle defects observed in RBFOX2 loss of function in human heart diseases and in experimental animal models (Sebastian et al. 2013),(Singh et al. 2018a),(Gallagher et al. 2011), (Homsy et al. 2015; McKean et al. 2016; Verma et al. 2016),(Wei et al. 2015),(Nutter et al. 2017; Nutter et al. 2016).

Using nanopore sequencing we validated previous findings that that AS of exons 6a/6b of Tpm1 are developmentally regulated in rat hearts and identified new full length transcripts of Tpm1 regulated during rat heart development. Here we showed that AS of exons $6 a$ vs $6 b$ were controlled antagonistically by RBFOX2 and PTBP. The exon 6a/6b is required for cooperative actin binding (Hammell and HitchcockDeGregori 1997). Therefore, the dynamic regulation of exon $6 a$ via RBFOX2 and PTBP during cardiac development is critical to ensure selective Tpm1 isoforms expressed in equilibrium to exert specific actin binding activity during different states of muscle contraction. 
Our results support the idea that RBFOX2 is a repressor of Tpm1 exon $6 a$ inclusion. Conversely, PTBP1 is an activator of exon $6 \mathrm{a}$, consistent with the previous reports (Lin and Tarn 2005; Llorian et al. 2010; Xue et al. 2009). The expression levels of both PTBP1 and RBFOX2 were high at embryonic stages but both were decreased at adult stages in rat hearts. While the predominant expression of muscle specific Tpm1 isoforms at adult stages was consistent with downregulation of PTBP1, the abundance of muscle specific Tpm1 isoforms at embryonic stages was in agreement with high levels of RBFOX2. The interplay between these RNA binding proteins in regulating Tpm1 AS correlates well with their different roles as repressors or activators of exon inclusion.

It is quite common that cardiac structural genes undergo cooperative AS regulation that determine their specific functions and expression profiles during cardiac development. Mutations in these structural genes including TPM1 are linked to human heart diseases. Our results using nanopore sequencing provide as an efficient way to reveal full length isoforms of cardiac structural genes and their regulation during heart development. In addition, our work may pave the way for future studies to determine the functional consequences of non-coding mutations on post-transcriptional regulation of cardiac structural genes using nanopore sequencing. 


\section{MATERIALS AND METHODS}

\section{Cell culture}

H9c2 cells (ATCC CRL-1446) were cultured and maintained in Dulbecco's modified Eagle's medium (DMEM) (ATCC 30-2002), supplemented with $10 \%$ fetal bovine serum (FBS, ATCC 30-2020) and 100 units/ml penicillin and streptomycin (Thermofisher Scientific 15140122).

\section{Transfections}

For siRNA-KD experiments, $\mathrm{H} 9 \mathrm{c} 2$ cells were seeded at $10^{6}$ cells per $100 \mathrm{~mm}$ dish and transfected with 20nM scrambled siRNA (Invitrogen AM4611), Rbfox2 siRNA (Invitrogen siRNA ID\# s96620) or PTBP siRNAs (Qiagen cat\# SI02649206 and SI04255146) using Lipofectamine RNAiMAX (Thermofisher Scientific). Cells were harvested 72 hours posttransfection for RNA or protein extraction. For rescue experiments, $3 \times 10^{6} \mathrm{H} 9 \mathrm{c} 2$ cells were transfected with eGFP (Sigma-Aldrich), human GFP-RBFOX2 (transcript variant 3) (Addgene, plasmid \#63086) or empty vector (pcDNA 5) together with scrambled or Rbfox2 specific siRNAs using Neon Nucleofection System (Thermofisher Scientific) as described previously (Verma et al. 2013). RNA was harvested 48 hours post-transfection.

\section{Nanopore sequencing with MinION}

RNA was extracted from cells using TRIzol (Invitrogen 15596-018) by following the manufacturer's protocol. For nanopore sequencing, three sets of E20 and three sets of $6 \mathrm{M}$ rat heart RNA (Zyagen) were used. Total cellular RNA was first poly(A) enriched (New England Biolabs S1550S) and then amplified using oligo-dT primers and template 
switching oligos using Oxford Nanopore Technologies (ONT) cDNA-PCR sequencing kit (PCS108) as described by the manufacturer. Samples were multiplexed using ONT barcodes. Pooled samples were sequencing on R9.4 flowcells for 36 . Reads were demultiplexed and base-called using Albacore and mapped to the rat genome (rn6) using the -splice function of minimap2 as described previously (Li 2016). Analysis pipeline is shown in Supplemental Figure 1.

\section{RT-qPCR}

Total RNA from cells and rat hearts (purchased from Zyagen) at E13 (pooled), E16 (pooled), E18 (pooled), E20 (pooled), post-natal day1 (D1) (pooled), and 6M (pooled) stages were extracted using Trizol. $2 \mu \mathrm{g}$ of total RNA was used for cDNA synthesis using

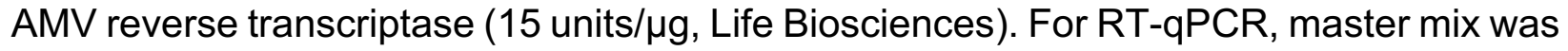
set up by mixing $5 \mu \mathrm{l}$ of cDNA, $3 \mu \mathrm{l}$ of $\mathrm{H}_{2} \mathrm{O}, 2 \mu \mathrm{l}$ of PCR gene specific primer (10X conc) (Table S1) and $10 \mu$ l of master mix (Roche 04707516001$)$ in $20 \mu$ reaction. The RT-qPCR was conducted using LightCycler 480 Instrument (Roche) using the following conditions: $95{ }^{\circ} \mathrm{C} 10 \mathrm{~s} ; 62{ }^{\circ} \mathrm{C} 15 \mathrm{~s} ; 72{ }^{\circ} \mathrm{C} 10 \mathrm{~s}$ for 40 cycles. Melting curve was obtained to ensure single product. $\Delta \mathrm{Ct}$ method was adopted for quantification. Semi-quantitative RT-PCR instead of RT-qPCR was used for determining Tpm1 short and Tpm1 long transcript levels due to the alternative splicing of exon 9a that generates two different sized DNA bands after amplification. $2 \mu \mathrm{g}$ of total RNA was used for cDNA synthesis using AMV

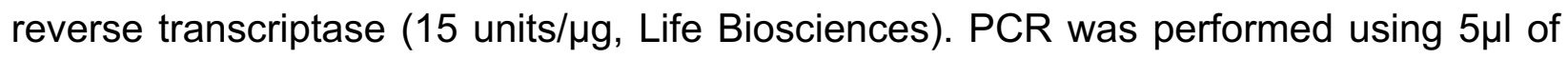
cDNA, $25 \mu \mathrm{M}$ dNTPs, 100ng of each gene specific forward and reverse primer and $0.2 \mu l$ of Biolase Taq polymerase (Bioline) in a $20 \mu \mathrm{L}$ reaction. The amplified products were 
analyzed on 5\% acrylamide gel. Hprt was used as an internal control for RT-PCR quantification.

\section{Western Blot}

The membrane was blocked with $5 \%$ dry fat-free milk solution in PBS containing $0.1 \%$ Tween (PBST) at RT for 1 hour and then incubated with indicated primary antibodies overnight at $4^{\circ} \mathrm{C}$. The membrane was washed with PBST for 15 minutes three times and incubated with HRP-conjugated secondary antibody for 1 hour at RT followed by three washes using PBST. Immobilon Western chemiluminescent (Millipore WBKLS0500) kit was used to detect HRP activity of the secondary antibody. The membrane was then imaged using ChemiDoc Touch imaging system (Bio-rad). Image $\mathrm{J}$ software was used for band intensity quantification. Primary antibodies used for this study are as follows: TPM1 (1:1000, Cell Signaling, D12H4), RBFOX2 (1:1000, Abcam, ab57154), PTBP1 (1:5000, a gift from Dr. Mariano Garcia-Blanco) and a-tubulin (1:20000, Sigma-Aldrich, T6074). 


\section{DATA AVAILABILITY}

Nanopore sequencing data was deposited to NCBI SRA database with project number PRJNA517125.

\section{ACKNOWLEDGEMENTS, FUNDING AND CONFLICT OF INTEREST}

This work was supported, in part, UTMB Department of Biochemistry and Molecular Biology Bridging funds; and a grant from the National Institutes of Health/ National Heart Lung Blood Institute [1R01HL135031], a grant from CPRIT [RP190556] and a grant from American Heart Association [20TPA35490206] to M.N.K-M. The contents of the manuscript are solely the responsibility of the authors and do not necessarily represent the official views of NHLBI of NIH. J.C. is a funded by a post-doctoral fellowship from American Heart Association [18POST3399018]. A.R. is supported by start-up funds from UTMB. We thank Dr. Garcia-Blanco for providing us PTBP1 antibody. Authors declare no conflict of interest. 


\section{REFERENCES}

Bai F, Wang L, Kawai M. 2013. A study of tropomyosin's role in cardiac function and disease using thin-filament reconstituted myocardium. J Muscle Res Cell Motil. 34(3-4):295-310.

Bailey K. 1948. Tropomyosin: A new asymmetric protein component of the muscle fibril. The Biochemical journal. 43(2):271-279.

Baralle FE, Giudice J. 2017. Alternative splicing as a regulator of development and tissue identity. Nat Rev Mol Cell Biol. 18(7):437-451.

Cibi DM, Mia MM, Guna Shekeran S, Yun LS, Sandireddy R, Gupta P, Hota M, Sun L, Ghosh S, Singh MK. 2019. Neural crest-specific deletion of rbfox2 in mice leads to craniofacial abnormalities including cleft palate. Elife. 8.

Consortium EP. 2012. An integrated encyclopedia of DNA elements in the human genome. Nature. 489(7414):57-74.

Crawford JB, Patton JG. 2006. Activation of alpha-tropomyosin exon 2 is regulated by the sr protein $9 \mathrm{~g} 8$ and heterogeneous nuclear ribonucleoproteins $\mathrm{h}$ and $\mathrm{f}$. Molecular and cellular biology. 26(23):8791-8802.

Davis CA, Hitz BC, Sloan CA, Chan ET, Davidson JM, Gabdank I, Hilton JA, Jain K, Baymuradov UK, Narayanan AK et al. 2018. The encyclopedia of DNA elements (encode): Data portal update. Nucleic Acids Res. 46(D1):D794-D801.

de Jong LC, Cree S, Lattimore V, Wiggins GAR, Spurdle AB, Miller A, Kennedy MA, Walker LC, Investigators K. 2017. Nanopore sequencing of full-length brca1 mrna transcripts reveals co-occurrence of known exon skipping events. Breast Cancer Res. 19.

Dube DK, McLean MD, Dube S, Poiesz BJ. 2014. Translational control of tropomyosin expression in vertebrate hearts. Anatomical record. 297(9):1585-1595.

Dye DT, Buvoli M, Mayer SA, Lin CH, Patton JG. 1998. Enhancer elements activate the weak 3 ' splice site of alpha-tropomyosin exon 2. Rna. 4(12):1523-1536.

England J, Granados-Riveron J, Polo-Parada L, Kuriakose D, Moore C, Brook JD, Rutland CS, Setchfield K, Gell C, Ghosh TK et al. 2017. Tropomyosin 1: Multiple roles in the developing heart and in the formation of congenital heart defects. Journal of molecular and cellular cardiology. 106:1-13.

Gallagher TL, Arribere JA, Geurts PA, Exner CRT, McDonald KL, Dill KK, Marr HL, Adkar SS, Garnett AT, Amacher SL et al. 2011. Rbfox-regulated alternative splicing is critical for zebrafish cardiac and skeletal muscle functions. Dev Biol. 359(2):251261.

Geeves MA, Hitchcock-DeGregori SE, Gunning PW. 2015. A systematic nomenclature for mammalian tropomyosin isoforms. J Muscle Res Cell Motil. 36(2):147-153.

Gooding C, Edge C, Lorenz M, Coelho MB, Winters M, Kaminski CF, Cherny D, Eperon IC, Smith CW. 2013a. Mbnl1 and ptb cooperate to repress splicing of tpm1 exon 3. Nucleic Acids Res. 41(9):4765-4782.

Gooding C, Edge C, Lorenz M, Coelho MB, Winters M, Kaminski CF, Cherny D, Eperon IC, Smith CWJ. 2013b. Mbnl1 and ptb cooperate to repress splicing of tpm1 exon 3. Nucleic Acids Research. 41(9):4765-4782. 
Gunning P, O'Neill G, Hardeman E. 2008. Tropomyosin-based regulation of the actin cytoskeleton in time and space. Physiological reviews. 88(1):1-35.

Gunning PW, Hardeman EC, Lappalainen P, Mulvihill DP. 2015. Tropomyosin - master regulator of actin filament function in the cytoskeleton. Journal of cell science. 128(16):2965-2974.

Gunning PW, Schevzov G, Kee AJ, Hardeman EC. 2005a. Tropomyosin isoforms: Divining rods for actin cytoskeleton function. Trends in cell biology. 15(6):333-341.

Gunning PW, Schevzov G, Kee AJ, Hardeman EC. 2005b. Tropomyosin isoforms: Divining rods for actin cytoskeleton function. Trends Cell Biol. 15(6):333-341.

Hammell RL, HitchcockDeGregori SE. 1996. Mapping the functional domains within the carboxyl terminus of alpha-tropomyosin encoded by the alternatively spliced ninth exon. J Biol Chem. 271(8):4236-4242.

Hammell RL, HitchcockDeGregori SE. 1997. The sequence of the alternatively spliced sixth exon of alpha-tropomyosin is critical for cooperative actin binding but not for interaction with troponin. J Biol Chem. 272(36):22409-22416.

Helfman DM, Cheley S, Kuismanen E, Finn LA, Yamawaki-Kataoka Y. 1986. Nonmuscle and muscle tropomyosin isoforms are expressed from a single gene by alternative rna splicing and polyadenylation. Molecular and cellular biology. 6(11):3582-3595.

Homsy J, Zaidi S, Shen Y, Ware JS, Samocha KE, Karczewski KJ, DePalma SR, McKean D, Wakimoto H, Gorham J et al. 2015. De novo mutations in congenital heart disease with neurodevelopmental and other congenital anomalies. Science. 350(6265):1262-1266.

Huang SC, Ou AC, Park J, Yu F, Yu B, Lee A, Yang G, Zhou A, Benz EJ, Jr. 2012. Rbfox2 promotes protein 4.1r exon 16 selection via u1 snrnp recruitment. Molecular and cellular biology. 32(2):513-526.

Jagatheesan G, Rajan S, Ahmed RP, Petrashevskaya N, Boivin G, Arteaga GM, Tae HJ, Liggett SB, Solaro RJ, Wieczorek DF. 2010. Striated muscle tropomyosin isoforms differentially regulate cardiac performance and myofilament calcium sensitivity. $\mathrm{J}$ Muscle Res Cell Motil. 31(3):227-239.

Jain M, Koren S, Miga KH, Quick J, Rand AC, Sasani TA, Tyson JR, Beggs AD, Dilthey AT, Fiddes IT et al. 2018. Nanopore sequencing and assembly of a human genome with ultra-long reads. Nat Biotechnol. 36(4):338-345.

Jangi M, Boutz PL, Paul P, Sharp PA. 2014. Rbfox2 controls autoregulation in rna-binding protein networks. Genes Dev. 28(6):637-651.

Jongbloed RJ, Marcelis CL, Doevendans PA, Schmeitz-Mulkens JM, Van Dockum WG, Geraedts JP, Smeets HJ. 2003. Variable clinical manifestation of a novel missense mutation in the alpha-tropomyosin (tpm1) gene in familial hypertrophic cardiomyopathy. Journal of the American College of Cardiology. 41(6):981-986.

Kalsotra A, Xiao X, Ward AJ, Castle JC, Johnson JM, Burge CB, Cooper TA. 2008. A postnatal switch of celf and mbnl proteins reprograms alternative splicing in the developing heart. Proc Natl Acad Sci U S A. 105(51):20333-20338.

Karam CN, Warren CM, Rajan S, de Tombe PP, Wieczorek DF, Solaro RJ. 2011. Expression of tropomyosin-kappa induces dilated cardiomyopathy and depresses cardiac myofilament tension by mechanisms involving cross-bridge dependent activation and altered tropomyosin phosphorylation. J Muscle Res Cell Motil. 31(56):315-322. 
Li H. 2016. Minimap and miniasm: Fast mapping and de novo assembly for noisy long sequences. Bioinformatics. 32(14):2103-2110.

Li H. 2018. Minimap2: Pairwise alignment for nucleotide sequences. Bioinformatics. 34(18):3094-3100.

Lin JC, Tarn WY. 2005. Exon selection in alpha-tropomyosin mrna is regulated by the antagonistic action of rbm4 and ptb. Molecular and cellular biology. 25(22):1011110121.

Lin JJ, Eppinga RD, Warren KS, McCrae KR. 2008. Human tropomyosin isoforms in the regulation of cytoskeleton functions. Advances in experimental medicine and biology. 644:201-222.

Llorian M, Schwartz S, Clark TA, Hollander D, Tan LY, Spellman R, Gordon A, Schweitzer AC, de la Grange P, Ast $G$ et al. 2010. Position-dependent alternative splicing activity revealed by global profiling of alternative splicing events regulated by ptb. Nature structural \& molecular biology. 17(9):1114-1123.

Lovci MT, Ghanem D, Marr H, Arnold J, Gee S, Parra M, Liang TY, Stark TJ, Gehman LT, Hoon S et al. 2013. Rbfox proteins regulate alternative mrna splicing through evolutionarily conserved rna bridges. Nature structural \& molecular biology. 20(12):1434-1442.

Lu H, Giordano F, Ning Z. 2016. Oxford nanopore minion sequencing and genome assembly. Genomics Proteomics Bioinformatics. 14(5):265-279.

Marques MA, de Oliveira GA. 2016. Cardiac troponin and tropomyosin: Structural and cellular perspectives to unveil the hypertrophic cardiomyopathy phenotype. Frontiers in physiology. 7:429.

Marston SB, Redwood CS. 1993. The essential role of tropomyosin in cooperative regulation of smooth muscle thin filament activity by caldesmon. J Biol Chem. 268(17):12317-12320.

McKean DM, Homsy J, Wakimoto H, Patel N, Gorham J, DePalma SR, Ware JS, Zaidi S, Ma W, Patel $\mathrm{N}$ et al. 2016. Loss of rna expression and allele-specific expression associated with congenital heart disease. Nat Commun. 7:12824.

Misra C, Bangru S, Lin F, Lam K, Koenig SN, Lubbers ER, Hedhli J, Murphy NP, Parker DJ, Dobrucki LW et al. 2020. Aberrant expression of a non-muscle rbfox2 isoform triggers cardiac conduction defects in myotonic dystrophy. Dev Cell. 52(6):748763 e746.

Moraczewska J, Nicholson-Flynn K, Hitchcock-DeGregori SE. 1999. The ends of tropomyosin are major determinants of actin affinity and myosin subfragment 1induced binding to f-actin in the open state. Biochemistry. 38(48):15885-15892.

Mullen MP, Smith CW, Patton JG, Nadal-Ginard B. 1991. Alpha-tropomyosin mutually exclusive exon selection: Competition between branchpoint/polypyrimidine tracts determines default exon choice. Genes Dev. 5(4):642-655.

Muthuchamy M, Pieples K, Rethinasamy P, Hoit B, Grupp IL, Boivin GP, Wolska B, Evans C, Solaro RJ, Wieczorek DF. 1999. Mouse model of a familial hypertrophic cardiomyopathy mutation in alpha-tropomyosin manifests cardiac dysfunction. Circulation research. 85(1):47-56.

Nutter CA, Jaworski E, Verma SK, Perez-Carrasco Y, Kuyumcu-Martinez MN. 2017. Developmentally regulated alternative splicing is perturbed in type 1 diabetic skeletal muscle. Muscle Nerve. 56(4):744-749. 
Nutter CA, Jaworski EA, Verma SK, Deshmukh V, Wang QL, Botvinnik OB, Lozano MJ, Abass IJ, ljaz T, Brasier AR et al. 2016. Dysregulation of rbfox2 is an early event in cardiac pathogenesis of diabetes. Cell Rep. 15(10):2200-2213.

Oikonomopoulos S, Wang YC, Djambazian H, Badescu D, Ragoussis J. 2016. Benchmarking of the oxford nanopore minion sequencing for quantitative and qualitative assessment of cdna populations. Scientific reports. 6:31602.

Perry SV. 2001. Vertebrate tropomyosin: Distribution, properties and function. J Muscle Res Cell Motil. 22(1):5-49.

Rajan S, Jagatheesan G, Karam CN, Alves ML, Bodi I, Schwartz A, Bulcao CF, D'Souza KM, Akhter SA, Boivin GP et al. 2010. Molecular and functional characterization of a novel cardiac-specific human tropomyosin isoform. Circulation. 121(3):410-418.

Rao JN, Rivera-Santiago R, Li XE, Lehman W, Dominguez R. 2012. Structural analysis of smooth muscle tropomyosin alpha and beta isoforms. J Biol Chem. 287(5):31653174.

Redwood C, Robinson P. 2013. Alpha-tropomyosin mutations in inherited cardiomyopathies. J Muscle Res Cell Motil. 34(3-4):285-294.

Schevzov G, Whittaker SP, Fath T, Lin JJ, Gunning PW. 2011. Tropomyosin isoforms and reagents. Bioarchitecture. 1(4):135-164.

Sebastian S, Faralli H, Yao ZZ, Rakopoulos P, Palii C, Cao Y, Singh K, Liu QC, Chu A, Aziz A et al. 2013. Tissue-specific splicing of a ubiquitously expressed transcription factor is essential for muscle differentiation. Gene Dev. 27(11):1247-1259.

Singh RK, Kolonin AM, Fiorotto ML, Cooper TA. 2018a. Rbfox-splicing factors maintain skeletal muscle mass by regulating calpain3 and proteostasis. Cell Rep. 24(1):197208.

Singh RK, Kolonin AM, Fiorotto ML, Cooper TA. 2018b. Rbfox-splicing factors maintain skeletal muscle mass by regulating calpain3 and proteostasis. Cell Rep. 24(1):197208.

Singh RK, Xia Z, Bland CS, Kalsotra A, Scavuzzo MA, Curk T, Ule J, Li W, Cooper TA. 2014. Rbfox2-coordinated alternative splicing of mef2d and rock2 controls myoblast fusion during myogenesis. Molecular cell. 55(4):592-603.

Sun S, Zhang Z, Fregoso O, Krainer AR. 2012. Mechanisms of activation and repression by the alternative splicing factors rbfox1/2. Rna. 18(2):274-283.

Thierfelder L, Watkins H, MacRae C, Lamas R, McKenna W, Vosberg HP, Seidman JG, Seidman CE. 1994. Alpha-tropomyosin and cardiac troponin t mutations cause familial hypertrophic cardiomyopathy: A disease of the sarcomere. Cell. 77(5):701712.

Thomas A, Rajan S, Thurston HL, Masineni SN, Dube P, Bose A, Muthu V, Dube S, Wieczorek DF, Poiesz BJ et al. 2010. Expression of a novel tropomyosin isoform in axolotl heart and skeletal muscle. Journal of cellular biochemistry. 110(4):875881.

Verma SK, Deshmukh V, Liu P, Nutter CA, Espejo R, Hung ML, Wang GS, Yeo GW, Kuyumcu-Martinez MN. 2013. Reactivation of fetal splicing programs in diabetic hearts is mediated by protein kinase c signaling. J Biol Chem. 288(49):3537235386. 
Verma SK, Deshmukh V, Nutter CA, Jaworski E, Jin WH, Wadhwa L, Abata J, Ricci M, Lincoln J, Martin JF et al. 2016. Rbfox2 function in rna metabolism is impaired in hypoplastic left heart syndrome patient hearts. Scientific reports. 6.

Wang ET, Sandberg R, Luo S, Khrebtukova I, Zhang L, Mayr C, Kingsmore SF, Schroth GP, Burge CB. 2008. Alternative isoform regulation in human tissue transcriptomes. Nature. 456(7221):470-476.

Wang L, Qu L, Yang L, Wang Y, Zhu H. 2020. Nanoreviser: An error-correction tool for nanopore sequencing based on a deep learning algorithm. Front Genet. 11:900.

Wei CL, Qiu JS, Zhou Y, Xue YC, Hu J, Ouyang KF, Banerjee I, Zhang CM, Chen BY, Li $\mathrm{HR}$ et al. 2015. Repression of the central splicing regulator rbfox2 is functionally linked to pressure overload-induced heart failure. Cell Rep. 10(9):1521-1533.

Wieczorek DF, Jagatheesan G, Rajan S. 2008. The role of tropomyosin in heart disease. Advances in experimental medicine and biology. 644:132-142.

Wolska BM, Wieczorek DM. 2003. The role of tropomyosin in the regulation of myocardial contraction and relaxation. Pflugers Archiv : European journal of physiology. 446(1):1-8.

Xue Y, Zhou Y, Wu T, Zhu T, Ji X, Kwon YS, Zhang C, Yeo G, Black DL, Sun H et al. 2009. Genome-wide analysis of ptb-rna interactions reveals a strategy used by the general splicing repressor to modulate exon inclusion or skipping. Molecular cell. 36(6):996-1006.

Yeo GW, Coufal NG, Liang TY, Peng GE, Fu XD, Gage FH. 2009. An rna code for the fox2 splicing regulator revealed by mapping rna-protein interactions in stem cells. Nature structural \& molecular biology. 16(2):130-137.

Yin Z, Ren J, Guo W. 2015. Sarcomeric protein isoform transitions in cardiac muscle: A journey to heart failure. Biochimica et biophysica acta. 1852(1):47-52. 
bioRxiv preprint doi: https://doi.org/10.1101/2020.07.30.229351; this version posted January 26, 2021. The copyright holder for this preprint (which was not certified by peer review) is the author/funder. All rights reserved. No reuse allowed without permission.

\section{FIGURES WITH FIGURE LEGENDS}


Figure 1

A

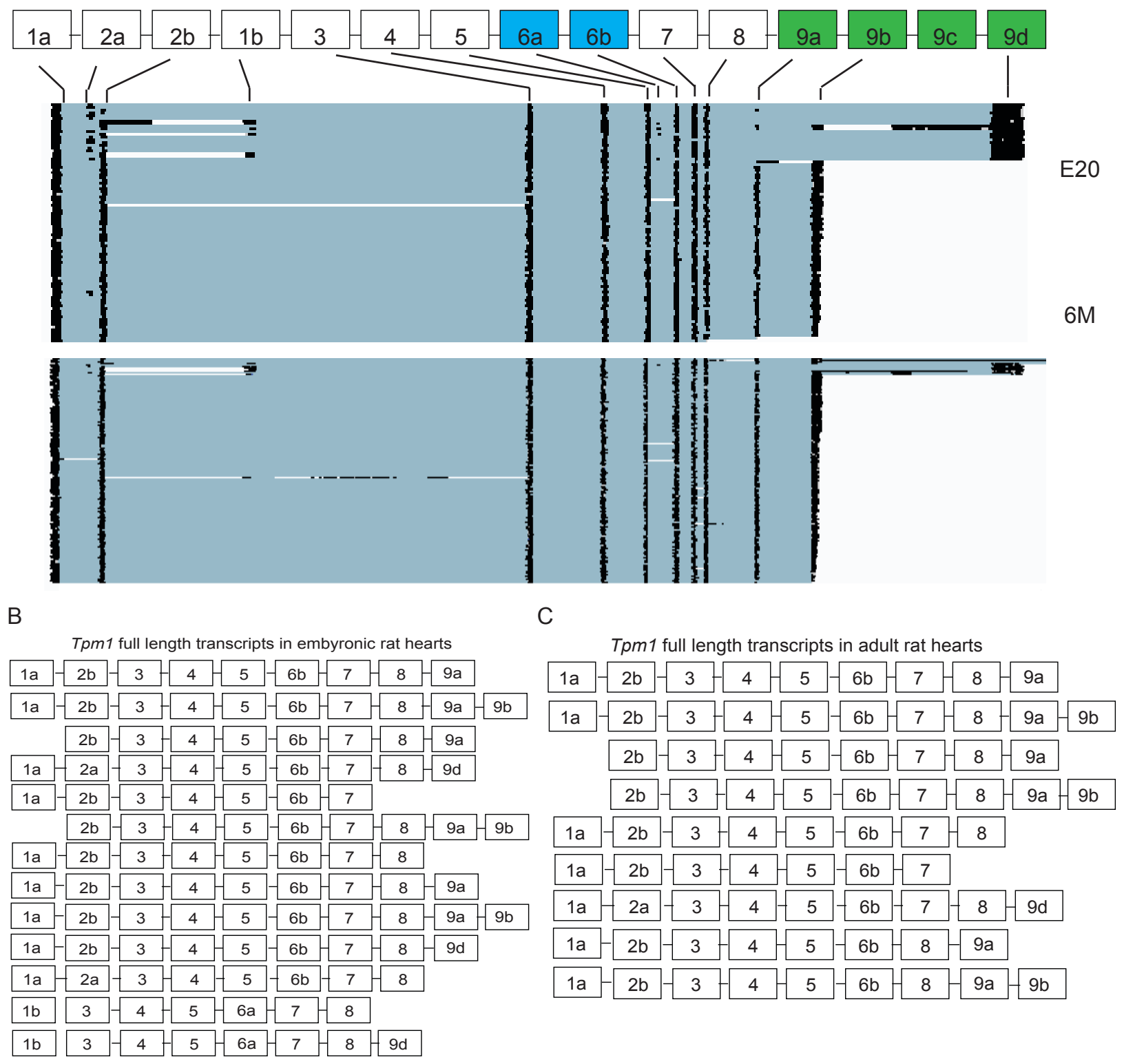

D E13 E16 E18 E20 D1 6M

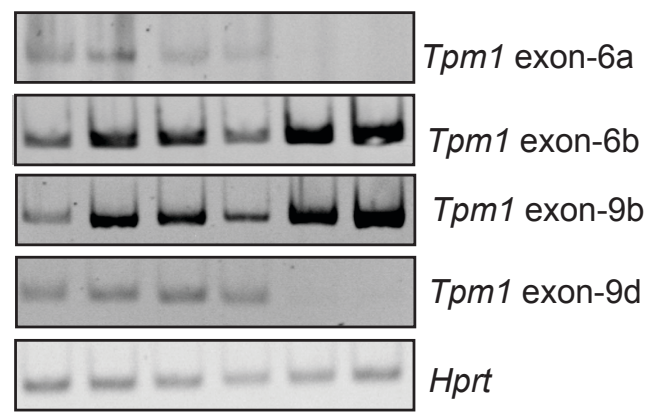


Figure 1. Identification of full length Tpm1 isoforms generated via alternative splicing during rat heart development using nanopore sequencing. (A) Representative images of nanopore sequencing reads mapped to $T p m 1$ gene in rat hearts at different developmental stages: embryonic day 20 (E20) and 6-months (6M) old $(n=3)$. Abundant full-length Tpm1 isoforms in embryonic day 20 rat hearts determined by nanopore reads. (C) Abundant full-length Tpm1 isoforms identified in 6 months old rat hearts by nanopore sequencing. (D) Relative ratio of $T p m 1$ isoforms that include exon $6 \mathrm{~b}$ vs $6 a$ or exon 9b vs 9d in rat hearts at E13, E16, E18, E20, D1 (1-day old) and 6M. 


\section{Figure 2}

A

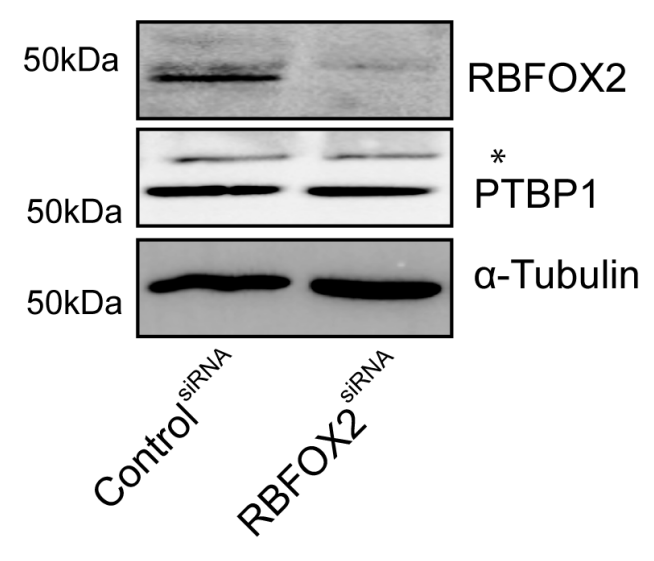

C

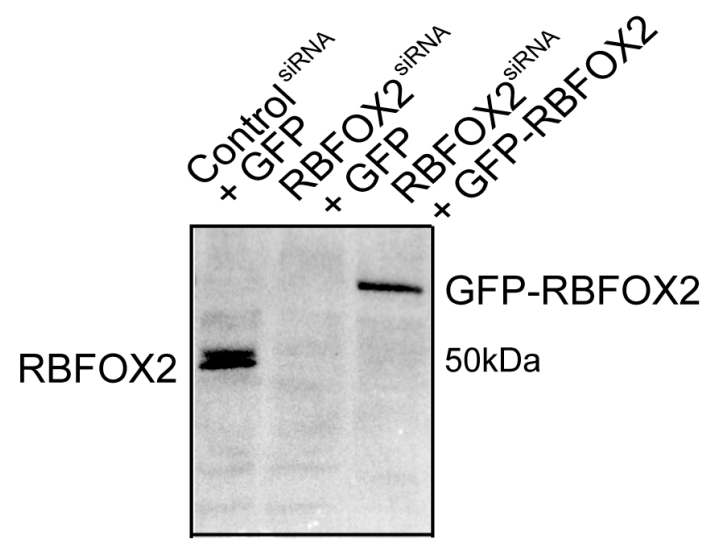

Anti-RBFOX2 antibody
B

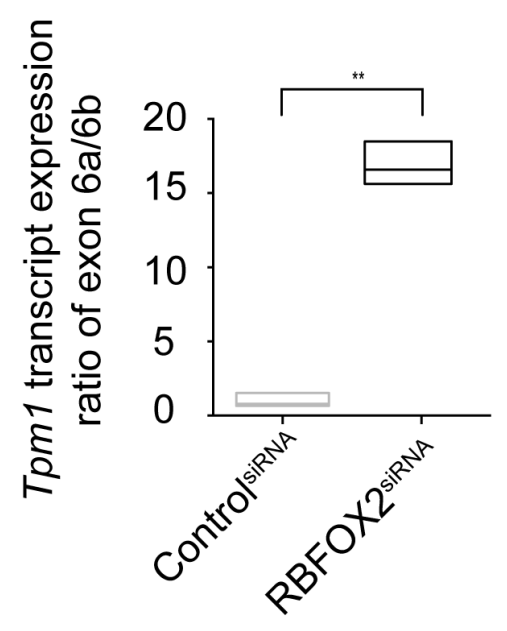

D

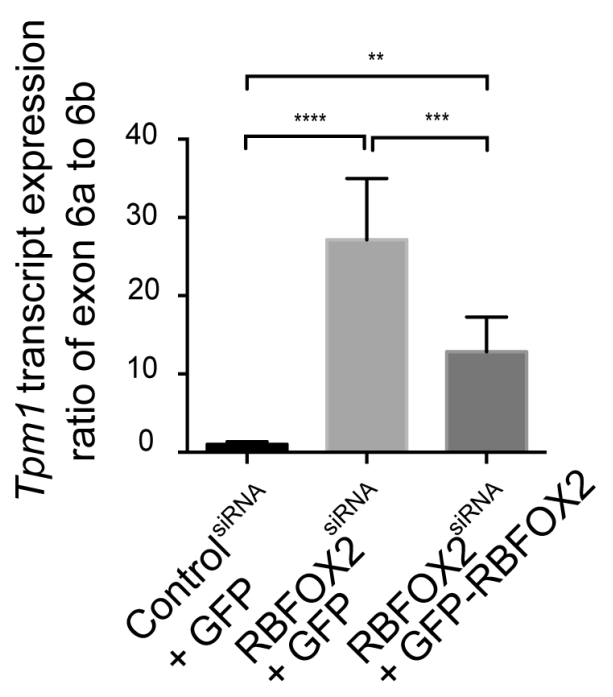


Figure 2. RBFOX2 regulates $A S$ of rat Tropomyosin 1 (Tpm1) exon 6a. (A) Representative Western blot images of RBFOX2 and PTBP1 in control and RBFOX2 depleted H9c2 cells. $\alpha$-tubulin was used as a loading control. (B) The ratio of expression levels of Tpm1 exons $6 a$ vs $6 b$ in control and RBFOX2 depleted H9c2 cells determined by RT-qPCR. Expression levels of Tpm1 exon $6 \mathrm{a}$ to $6 \mathrm{~b}$ in control cells were normalized to 1. Data represent means $\pm S D$. Statistical significance was calculated using t-test to compare two different groups in three independent experiments $(n=3) .{ }^{* *} p=0.013$. GFPREBFOX2 rescue experiments: (C) Western blot analysis of endogenous or GFP- tagged RBFOX2 protein in (lane1) scrambled siRNA treated, (lane 2) RBFOX2 siRNA treated, (lane 3) RBFOX2 siRNA treated H9c2 cells ectopically expressing of GFP or GFPRBFOX2 using anti-RBFOX2 antibody. (D) The expression level ratios of Tpm1 transcripts containing exons $6 a$ vs $6 \mathrm{~b}$ in control, RBFOX2 depleted, or RBFOX2 depleted GFP or GFP-RBFOX2 expressing cells. Expression ratios in control (1) cells were normalized to 1 . Data represent means $\pm S D$. Statistical significance was calculated using one-way ANOVA to compare three different groups in three independent experiments $(n=3)$. P-value for Control ${ }^{\text {siRnA }}+G F P$ vs. RBFOX2 ${ }^{\text {siRNA }}+$ GFP is $p<0.000001$; for RBFOX2 $2^{\text {iRNA }_{+}}$GFP vs. RBFOX2 ${ }^{\text {siRnA }}+$ GFP-RBFOX2 is $p=0.000683$; for Control$^{\mathrm{siRNA}}+$ GFP vs. RBFOX2 ${ }^{\mathrm{siRNA}}+$ GFP-RBFOX2 is $p=0.003409$. 
Figure 3

A

Part of TPM1

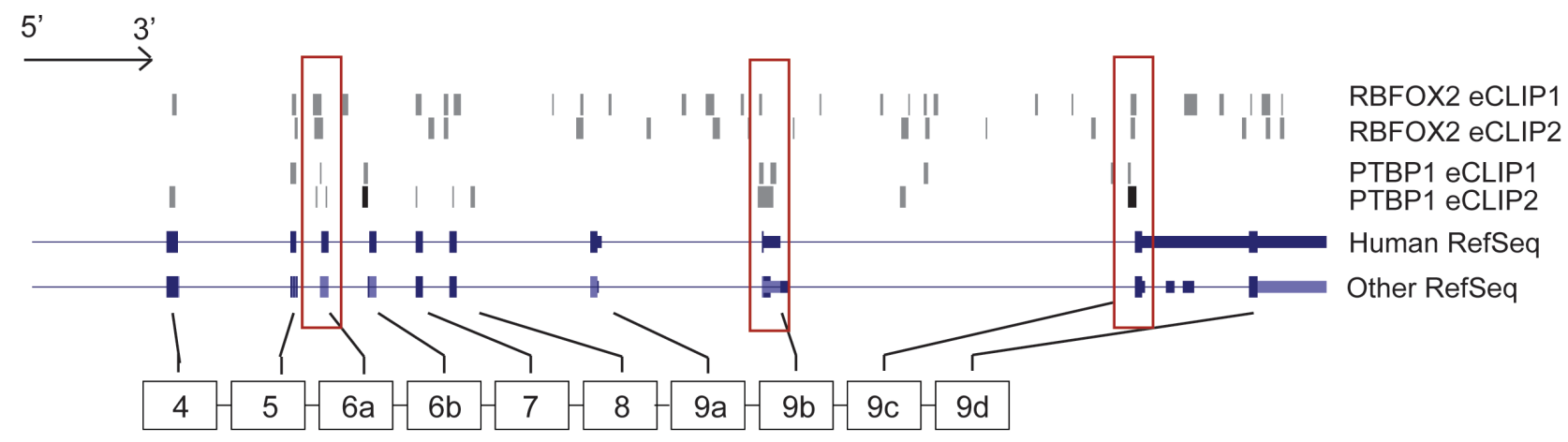

B

C

\section{Exon 9b}

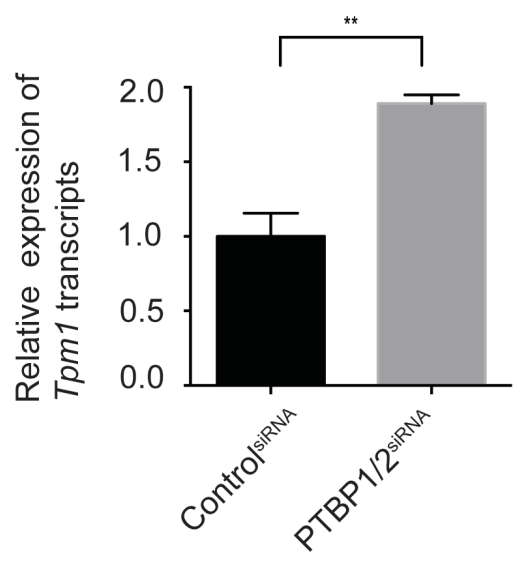

E

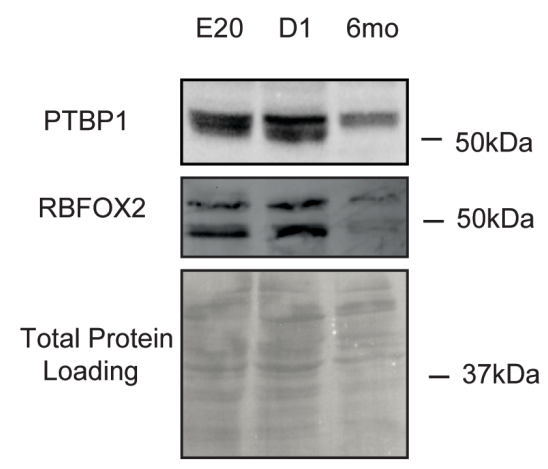

D

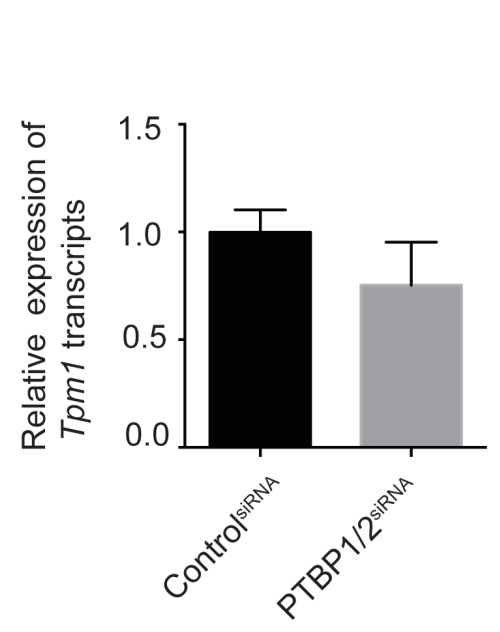

Exon 9d
Exon 6a/6b

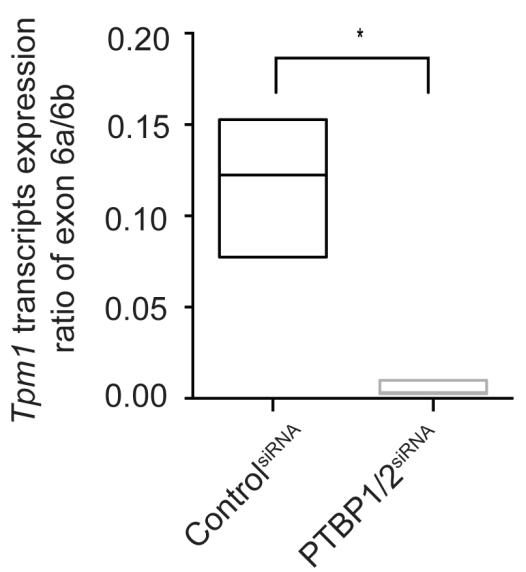


Figure 3. PTBP controls developmentally regulated AS of Tpm1 antagonistically to RBFOX2. (A) RBFOX2 eCLIP and PTBP1 eCLIP-seq reads mapped to the human Tpm1 gene. (B) Expression levels of Tpm1 transcripts containing exon 9b (muscle) in H9c2 cells treated with control or PTBP1/2 siRNA. mRNA levels in control cells were normalized to 1. Statistical significance was calculated using t-test to compare two different groups in three independent experiments $(n=3)$. P-value is represented as ${ }^{* *} p=0.0050$. (C) Expression levels of Tpm1 transcripts containing exon 9d (non-muscle) in H9c2 cells treated with control or PTBP1/2 siRNA. mRNA levels in control cells were normalized to 1. (D) Expression of $T p m 1$ transcripts containing exon $6 a$ vs $6 \mathrm{~b}$ in $\mathrm{H} 9 \mathrm{c} 2$ cells treated with control or PTBP1/2 siRNA. Data represent means \pm SD. Expression ratio of $T p m 1$ exon $6 a$ to $6 \mathrm{~b}$ in control cells were normalized to 1 . Statistical significance was calculated using t-test to compare two different groups in three independent experiments $(n=3)$. P-value is represented as * $p=0.0347$. (E) Western blot analysis of PTBP1 and RBFOX2 in rat hearts at different embryonic and postnatal stages. Even protein loading was monitored by Ponceau S stain of the membrane. 
Figure 4

A Rat Tpm2

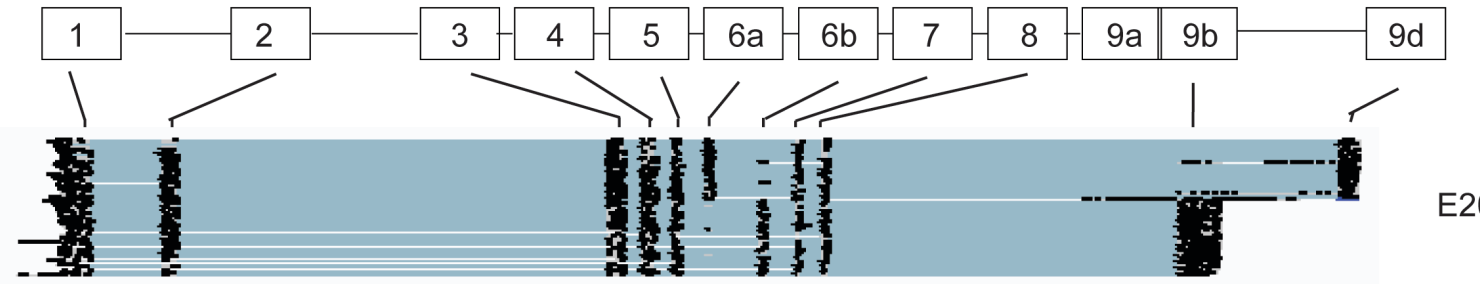

근

나눈

6M

B

Rat Tpm3
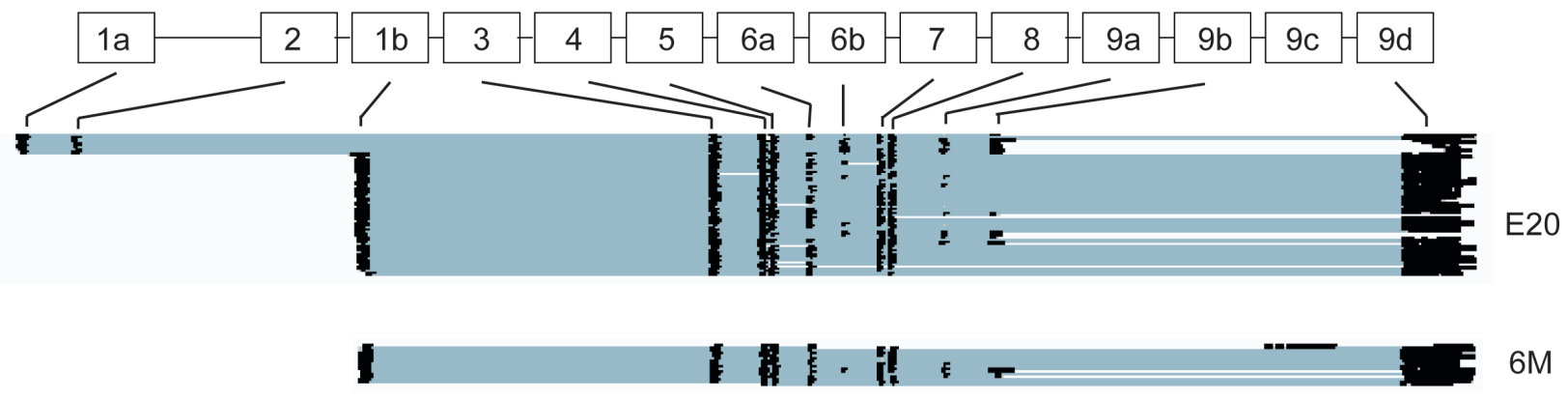

C

Rat Tpm4

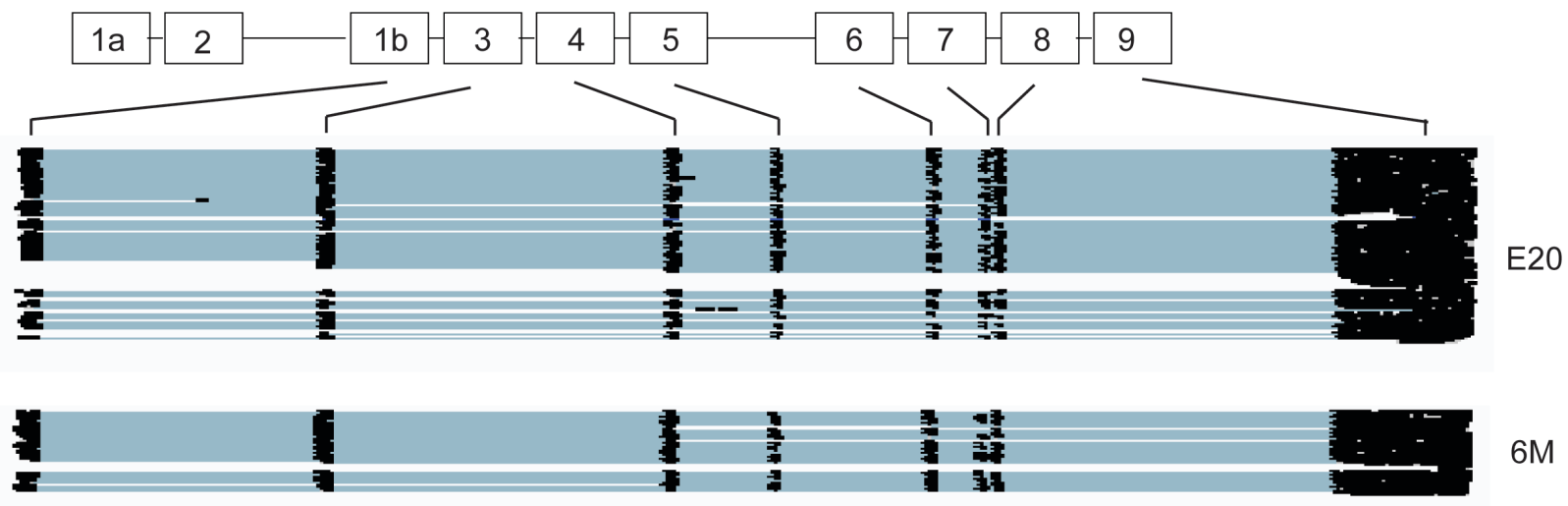


bioRxiv preprint doi: https://doi.org/10.1101/2020.07.30.229351; this version posted January 26, 2021. The copyright holder for this preprint (which was not certified by peer review) is the author/funder. All rights reserved. No reuse allowed without permission.

Figure 4. Full-length isoforms of Tpm2 (A), Tpm3 (B) and Tpm4 (C) identified by nanopore sequencing in embryonic day 20 (E20) and 6-months old (6M) rat hearts. 


\section{SUPPORTING INFORMATION (FIGURES AND TABLES)}

\section{Supplemental Figure 1.}

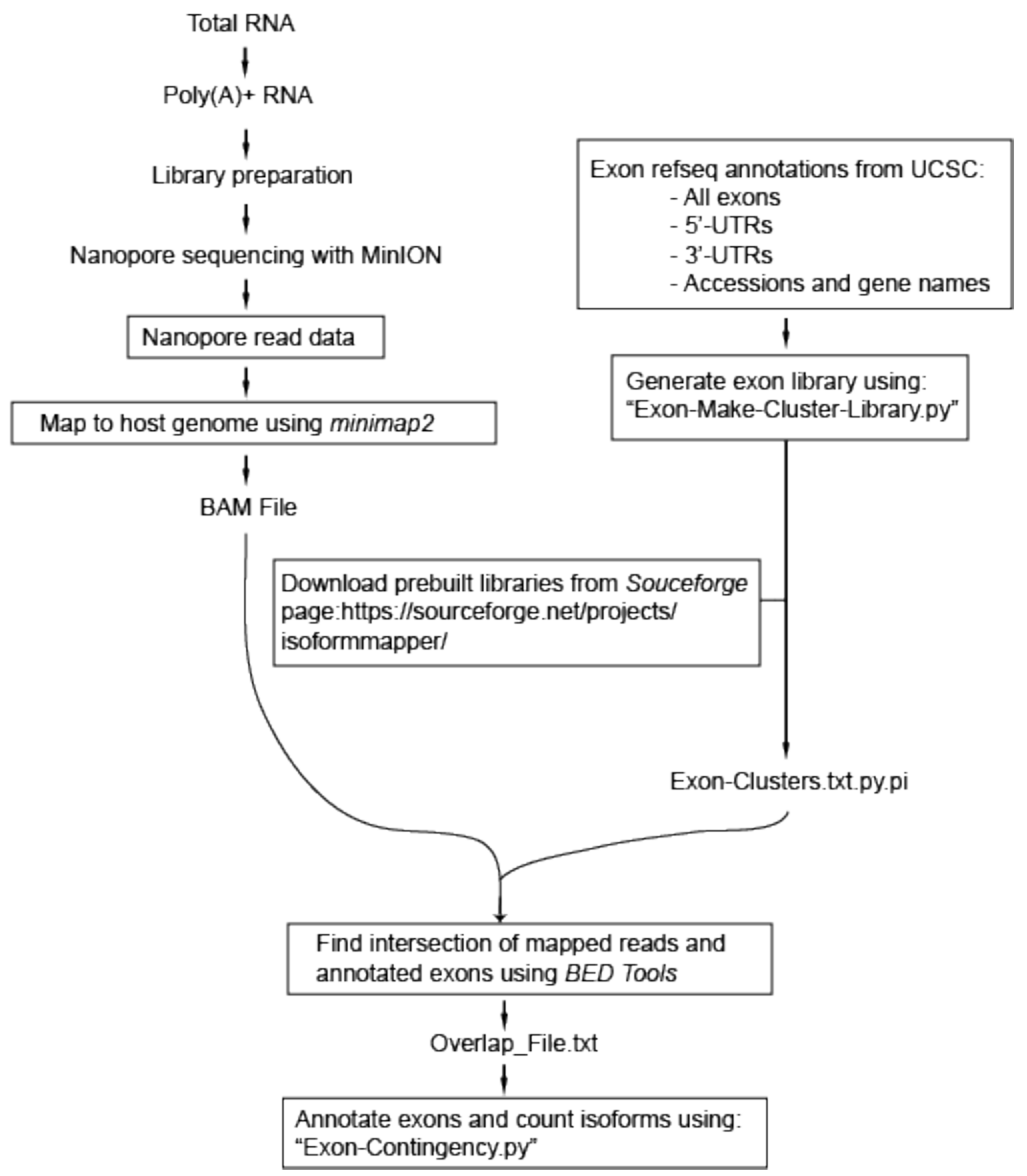

Figure S1. Workflow for nanopore cDNA sequencing. 


\section{Supplemental Table 1}

\begin{tabular}{|c|c|c|c|c|c|}
\hline $\begin{array}{l}\text { Gene } \\
\text { name }\end{array}$ & Species & $\begin{array}{l}\text { Gene } \\
\text { ID }\end{array}$ & $\begin{array}{l}\text { Analysis } \\
\text { target }\end{array}$ & $\begin{array}{l}\text { Forward primer } \\
\left(5^{\prime} \text { to } 3^{\prime}\right)\end{array}$ & $\begin{array}{l}\text { Reverse primer } \\
\left(3^{\prime} \text { to 5') }\right.\end{array}$ \\
\hline Tpm1 & Rat & $\begin{array}{c}\text { ENSR } \\
\text { NOG0 } \\
00000 \\
18184\end{array}$ & $\begin{array}{l}\text { Short-Tpm1 } \\
\text { (Exon7- } \\
\text { exon9b) }\end{array}$ & $\begin{array}{l}\text { GAAGACAAAT } \\
\text { ATGAAGAGGA } \\
\text { GATCAAG }\end{array}$ & $\begin{array}{l}\text { AATAGCAAACA } \\
\text { GGAATAGCGTA } \\
\text { CA }\end{array}$ \\
\hline Tpm1 & Rat & $\begin{array}{c}\text { ENSR } \\
\text { NOG0 } \\
00000 \\
18184\end{array}$ & $\begin{array}{l}\text { Long-Tpm1 } \\
\text { (Exon7- } \\
\text { exon9d) }\end{array}$ & $\begin{array}{l}\text { GAAGACAAAT } \\
\text { ATGAAGAGGA } \\
\text { GATCAAG }\end{array}$ & $\begin{array}{l}\text { CTGGTGCATAC } \\
\text { TAAGGTTTTCTT } \\
\text { СTTT }\end{array}$ \\
\hline Tpm1 & Rat & $\begin{array}{c}\text { ENSR } \\
\text { NOG0 } \\
00000 \\
18184\end{array}$ & $\begin{array}{l}\text { Exon4- } \\
\text { exon6a }\end{array}$ & $\begin{array}{l}\text { AAGATGCTGA } \\
\text { CCGAAAGTAT } \\
\text { GAAG }\end{array}$ & $\begin{array}{l}\text { GCTTTCAAGGT } \\
\text { CTGATCCATTA } \\
\text { TTCT }\end{array}$ \\
\hline Tpm1 & Rat & $\begin{array}{c}\text { ENSR } \\
\text { NOG0 } \\
00000 \\
18184\end{array}$ & $\begin{array}{l}\text { Exon4- } \\
\text { exon6b }\end{array}$ & $\begin{array}{l}\text { AAGATGCTGA } \\
\text { CCGAAAGTAT } \\
\text { GAAG }\end{array}$ & $\begin{array}{l}\text { TGAGCCTCCAG } \\
\text { TGACTTCAA }\end{array}$ \\
\hline
\end{tabular}




\begin{tabular}{|l|l|l|l|l|l|}
\hline Hprt & Rat & ENSR & Exon2- & CTCATGGACT & GCAGGTCAGCA \\
& & NOT0 & exon3 & GATTATGGAC & AAGAACTTATA \\
& & 00000 & & AGGAC & GCC \\
& & 45153. & & & \\
& & 3 & & & \\
\hline
\end{tabular}

Table S1. Primer list for PCR reactions. 